\title{
Tematización de los servicios hotel residencial Gibara, apuesta al turismo cultural desde el destino Holguín
}

\author{
Thematization of the services hotel residencial Gibara, bet on cultural \\ tourism from the destination Holguín
}

Evelina Cardet Fernández. ${ }^{1}$, Alfredo Santiago Ricardo Miranda. ${ }^{2}$ \& Alfredo Santiago Ricardo Miranda ${ }^{3}$

\begin{abstract}
The 21st century imposes a great challenge for Latin America and the Caribbean: diversify its tourism offer by sustainably managing its cultural heritage. To this end, it is proposed that every city, region or country with cultural resources and tourist attractions must exploit them sustainably to offer a different product capable of satisfying the interests of the various markets. The thematization of hotel services is a modern strategy assumed by destinations that are looking for new ways of attracting their clients, which is carried out with the objective of transmitting to the client a different idea that complements their general perception of the service. Gibara is a fascinating coastal city located north of the province of Holguin that has great potential and plenty of historical and cultural attractions. Therefore, it is the interest of the Government and the Ministry of Tourism (MINTUR) management in the province, to promote the sustainable tourism development of the municipality for the period 2016-2030 by creating new offers related to the historical-cultural value of the city. Taking into account the above, the present investigation was developed with the aim of designing the thematization of the services of the Residencial Gibara Hotel, based on the seven wonders, recreating a transition from those of the ancient world to those of Gibara and taking advantage of the historical values - cultural facilities and the environment, in order to enhance cultural tourism at the destination and to contribute to the diversification and differentiation of the city's tourist offer.
\end{abstract}

Key Words: Theming, Hotel Services, Cultural Tourism

\footnotetext{
${ }^{1}$ MsC. Universidad de Holguín, evelina@uho.edu.cu

${ }^{2}$ Lic. Complejo Turístico Gibara, alfredo324@ nauta.cu

${ }^{3} \mathrm{MsC}$. Universidad de Holguín, rpalaof@uho.edu.cu
} 


\section{Resumen}

El siglo XXI impone un gran desafío para América Latina y el Caribe: diversificar su oferta turística gestionando de manera sostenible su patrimonio cultural. Para ello se plantea que toda ciudad, región o país con recursos y atractivos turísticos culturales debe explotarlos sosteniblemente para ofrecer un producto diferente capaz de satisfacer los intereses de los diversos mercados. La tematización de los servicios hoteleros es una estrategia moderna asumida por los destinos que buscan nuevas formas de atracción de sus clientes que se realiza con el objetivo de transmitir una idea diferente que complemente su percepción general del servicio. Gibara es una fascinante ciudad costera ubicada al norte de la provincia de Holguín que cuenta con grandes potencialidades y sobrados atractivos histórico-culturales. Por tanto, es interés de la dirección del Gobierno y el Ministerio del Turismo (Mintur) en la provincia, potenciar el desarrollo turístico sostenible del municipio para el período 2016-2030 mediante la creación de nuevas ofertas relacionadas con el valor histórico-cultural de la ciudad. Teniendo en cuenta lo expuesto anteriormente se desarrolló la presente investigación con el objetivo de diseñar la tematización de los servicios del Hotel Residencial Gibara, basada en las siete maravillas, recreando una transición desde las del mundo antiguo hasta las de la localidad y aprovechando los valores histórico - culturales de la instalación y del entorno, en aras de potenciar el turismo cultural en el destino y para contribuir a la diversificación y diferenciación de la oferta turística de la ciudad.

Palabras Clave: Tematización, Servicios Hoteleros, Turismo Cultural

\section{Introducción}

El turismo ha llegado a posicionarse entre los sectores más importantes para la economía mundial, por ello demanda de acciones que garanticen el correcto aprovechamiento de cada destino con los que cuenta un país, así como la utilización de cada recurso para el diseño de ofertas turísticas, cada vez más únicas para satisfacer las exigencias del turista de estos tiempos. La integración de los diferentes recursos turísticos de una región con el desarrollo correspondiente de esta actividad no sólo logra dinamizarla, es además una oportunidad de avance socioeconómico, cultural y político. En el actual siglo el turismo desarrolla su actividad en un entorno económico globalizado, de gran incertidumbre y profundamente cambiante, en el que se vislumbran nuevas tendencias y retos que los destinos han de ir abordando para consolidar, al menos, los niveles de competitividad alcanzados, y mantener un sector que en los últimos años ha experimentado un importante crecimiento.

Entre las principales modalidades turísticas que se desarrollan en el mundo de hoy están las siguientes: Turismo de sol y playa, cultural, de congresos y convenciones, deportivo, náutico, académico y científico, de naturaleza, de salud; entre otras. A pesar de que la modalidad del turismo de sol y playa ha sido y aún hoy continúa siendo, el segmento de mercado que aporta mayores flujos de turistas a escala global, a la entrada del siglo XXI América Latina y el Caribe tienen un gran desafío: diversificar su oferta turística y gestionar de manera sostenible su patrimonio cultural y natural. Surge así, la necesidad 
de potenciar como modalidad emergente, el turismo cultural, entendido como el segmento que ofrece al visitante un conocimiento más profundo de otras culturas, costumbres y tradiciones, en el cual el patrimonio cultural juega un papel fundamental.

El turismo no es una actividad nueva en Cuba, sus inicios se remontan a los primeros años del pasado siglo donde la presencia estadounidense no solo tenía motivaciones de ocio y placer, sino que estaba relacionado con la penetración económica. En la década del 90 se manifiesta un incremento sostenido de los indicadores turísticos y ocurre la última reestructuración en esta actividad, cuando se crea el Ministerio de Turismo. A partir de este período, el sector se va convirtiendo paulatinamente en el principal motor impulsor de la economía y en una prioridad en el reacomodo del funcionamiento de todo el país.

La actualización de los Lineamientos de la Política Económica y Social del Partido y la Revolución para el período 2016-2021, aprobados por el VII Congreso del Partido Comunista de Cuba en abril de 2017 (Documentos VII Congreso PCC, 2017), en lo referente a la Política para el Turismo, en el número 209 plantea: La actividad turística deberá tener un crecimiento acelerado que garantice la sostenibilidad y dinamice la economía, incrementando de manera sostenida los ingresos y las utilidades, diversificando los mercados emisores y segmentos de clientes, y maximizando el ingreso medio por turista.

El archipiélago cubano tiene la suerte de tener muchos factores a su favor: tiempo favorable que ayuda al turismo de sol y playa; patrimonio histórico-cultural exquisito; parajes y paisajes de belleza natural; flora y fauna muy diversa y una gastronomía inigualable que lo hace único. Por eso, es elegido por los turistas en sus períodos vacacionales como destino para disfrutar del tiempo libre y ocio; debido a que tiene muchos destinos con una gran variedad de actividades hechas a la medida de cada turista; ya sea descanso, relax, sol y playa, cultura e historia, negocios y congresos, gastronomía... todo lo que desean los turistas lo pueden encontrar.

Gibara, también conocida como la Villa Blanca de los Cangrejos, la Perla Hermosa de Oriente o la Villa de Ensueños, es una fascinante ciudad costera situada al noroeste de la provincia de Holguín, es la capital de un municipio que cuenta con una gran potencialidad y sobrados atractivos para el desarrollo del turismo de ciudad y de naturaleza, además es sede de eventos de gran convocatoria como el Festival Internacional de Cine. Su centro histórico fue declarado Monumento Nacional desde el año 2004, condición que aun en la actualidad ostenta con orgullo.

En el proceso de desarrollo turístico se creó en 2011 la Empresa Integral Turística Gibara (EITG) Sucursal de la Corporación Cubanacán S.A., que en 2017 pasa a ser administrada por la prestigiosa cadena española Iberostar Hotels and Resorts y desde 2019 se convierte en el Complejo Turístico Gibara nuevamente subordinado a Cubanacán S.A.

El Complejo posee cuatro hoteles: Ordoño, Arsenita, Plaza Colón y Bahía del Almirante con 27, 12, 14 y 6 habitaciones respectivamente; más el Hostal Buena Vista con 4. De igual manera la Empresa ExpoHolguín ha abierto la Casa de Alojamiento Jibamar con 6 habitaciones de mediano estándar y servicios de restauración, lo que suma un total de 69 
capacidades de alojamiento turístico en el sector estatal, además de varios restaurantes especializados de los hoteles como El Faro, se cuenta con opciones extrahoteleras entre las que destacan el restaurante Río de Mares del Club Náutico, el Centro Recreativo Cultural El Siglo XX y el snack bar La Loja; todas gestionadas por el referido sector estatal. Por su parte el sector no estatal en la ciudad tiene una significativa participación contando con 57 casas de renta con 78 habitaciones y 22 restaurantes.

La Villa Blanca, luego de ser lanzada como destino turístico, en la XXXVII Feria Internacional de Turismo, FIT Cuba 2017, cerró el año 2018 con un 26.4\% de crecimiento respecto al año anterior, pero en 2019 tuvo un importante decrecimiento debido entre otros elementos a problemas en la gestión comercial y al mal estado de los viales.

Muchas son las oportunidades que avalan a este destino para el desarrollo del turismo cultural, sin embargo, aún son innumerables las acciones a desarrollar para lograr una mayor diversificación y diferenciación de la oferta existente, una de ellas, a través de la tematización de los servicios hoteleros, fundamentalmente en el caso de una ciudad que comienza a posicionarse frente a destinos de turismo de ciudad dentro y fuera del propio país. Por estas razones, es de total interés para las autoridades del Mintur y el gobierno la explotación de todos los recursos disponibles de forma tal que su adecuada gestión contribuya a diversificar y diferenciar la oferta turística en el destino Gibara.

\section{Diseño de los servicios hoteleros}

Muchos servicios turísticos, especialmente los servicios hoteleros, se caracterizan por un alto grado de interacción personal, donde el profesional implicado en el contacto directo con el cliente representa a la empresa, define el producto y lo promueve directamente hacia el consumidor. García Garazo (2004) plantea que Bowen y Schneider (1988) sugieren que las empresas de servicios deberían alcanzar un clima interno que propicie un impacto positivo en las actitudes y en los comportamientos del personal de contacto y, por esta vía, en la calidad de servicio percibida por los clientes. En otras palabras, los directivos deben comercializar internamente "una mentalidad de servicio" y gestionar eficazmente las prácticas organizativas para asegurar que las actitudes y los comportamientos del personal de contacto conduzcan a proporcionar un servicio de calidad.

La tematización hotelera es una de las tendencias que viene siendo desarrollada por algunas empresas del turismo y ocio que buscan satisfacer una demanda afín a una determinada marca. Hay diferentes formas de tematizar un hotel, empleando un tema central para todo el hotel, tematizando solo las habitaciones o bien tematizando solo una zona. Un hotel temático tiene que transmitir un concepto e idea principal, y la dirección debe no solo conservar sino alentar a través de sus colaboradores la misión del establecimiento que es la de conseguir que los clientes disfruten durante su estancia de un lugar diferente que ofrece algo más que una simple habitación. Cada empleado será en su caso un conocedor y un experto de lo que expresa el tema del hotel, y lo que está relacionado con él. Todo aquello que enriquezca el concepto principal deberá ser potenciado, hay que lograr que a través del tiempo se vaya recordando con actividades y 
acciones diversas para que el cliente sienta que está en un espacio singular (MenéndezLópez, 2018).

Por su parte, el diseño de servicios hoteleros con la incorporación de atractivos culturales que respondan a las exigencias actuales de la demanda y sean capaces de aportar una experiencia única e inolvidable, constituye una oportunidad para ofrecer un servicio de calidad exclusivo que dejará su huella en la mente del cliente y contribuirá decisivamente a la diferenciación de la oferta turística de cualquier destino.

Por tanto, el diseño de la tematización de los servicios de un hotel es un proceso que, según muchos autores, presupone la aplicación de un procedimiento que esté basado en una secuencia lógica de pasos, los que de manera general consideran la determinación de las oportunidades del entorno, la concepción y diseño de los servicios propiamente dichos, su comercialización, seguimiento y control durante la explotación.

Por otra parte, la evolución del mercado turístico, de los canales (internet) y por supuesto, del propio comportamiento del viajero, han redefinido las reglas de juego y las tendencias en el marketing turístico, que apunta hacia un cambio en la forma en que se configura el producto turístico, no sólo como una mera agrupación de servicios, sino como una oferta integral, dinámica y flexible, que responde a una experiencia demandada por el cliente (García, Esther 2013).

El marketing experiencial es una herramienta estratégica que permite construir un vínculo emocional y su objetivo es que exista una conexión semejante entre el producto, su consumo y el consumidor, lo cual contribuirá a la fidelidad de este y a la repetición de compra. Es además el resultado de los cambios producidos en el mercado en los últimos tiempos, en el que se ha pasado de vender productos y servicios a vender experiencias, y son estas, en última instancia, las que van a permitir a las empresas, en un contexto de fuerte competencia, diferenciarse y justificar precios más elevados (Fernández-Serrano, 2018)

Otra de las novedades de los últimos años en el negocio hotelero es la creación, actualización o rediseño de pequeños establecimientos, casas o edificios con algún tipo de singularidad que, aprovechando las nuevas tendencias del turismo de interior, cultural, de naturaleza o de simple descanso para los que "huyen" de las grandes ciudades, se han constituido en una oferta diferenciada que cada día tiene una mayor demanda (GonzálezSainz, 2019)

Al considerar lo anterior, en Cuba y particularmente en la región oriental (con mayor nivel de aplicación en Holguín y Santiago de Cuba), se han realizado investigaciones que sirven de sustento teórico a la presente pues en las mismas, de alguna manera se aborda la tematización de los servicios hoteleros. Entre los trabajos consultados se pueden citar: Jiménez-Gómez 2012, Propuesta de diseño de los servicios del Hotel E Ordoño en el Municipio Turístico Gibara; Velázquez-San Martín 2015, Diseño de los servicios del Hotel E Saratoga Holguín; Vinent-Ferrer 2016, Diseño de los servicios del Hotel E Imperial de Santiago de Cuba; Graña-Mariño 2017, Diseño de los servicios del Hotel E Bahía del Almirante en Gibara e Hidalgo - González 2018, Diseño de los servicios del 
Hotel Vallado en Gibara. A través del análisis de las investigaciones referidas anteriormente, teniendo en cuenta todo lo concerniente al estado del arte de los servicios hoteleros y su tematización para hoteles de ciudad en Cuba, y las potencialidades de Gibara como destino turístico; se determinó elaborar un nuevo procedimiento para el diseño de la tematización de los servicios del Hotel Residencial en dicha ciudad, partiendo del procedimiento propuesto por Hidalgo-González 2018, para el diseño de los servicios del Hotel Vallado y teniendo en cuenta que el Residencial es un hotel de ciudad que no pertenece a la marca Encanto y además contará con servicios de cinco estrellas. El nuevo procedimiento, quedó estructurado en tres fases en forma de sistema y un total de 16 pasos, tal y como se muestra en la figura 1.

Como argumento central para la tematización del hotel se propone recrear la historia de las maravillas del mundo antiguo y moderno, de las ciudades maravillas, de las maravillas de la arquitectura cubana y de las de Gibara.

\section{Fase 1. Preparación inicial}

Los servicios del Hotel Residencial son de gran significación e importancia para el destino turístico Gibara; por lo que, para el diseño de su tematización, se parte de crear un equipo de trabajo integrado por 7 especialistas (directivos, trabajadores con experiencia en la actividad y profesionales de diferentes entidades rectoras del turismo e instituciones vinculadas al sector en el territorio), así como a sus futuros trabajadores lo que logra un alto grado de compromiso y sentido de pertenencia, de manera que sean capaces de utilizar

sus conocimientos y experiencias en aras de contribuir a conformar un producto sostenible, rentable económicamente, que satisfaga las necesidades del cliente y contribuya a diferenciar y diversificar la oferta turística del destino. El proceso de capacitación estuvo dirigido básicamente a la actualización de los especialistas en cuanto a tendencias actuales de los servicios hoteleros, tematización de hoteles, historia de las maravillas del mundo antiguo y moderno, de las ciudades maravillas, de las maravillas de la arquitectura cubana y las de Gibara y características de los servicios de los hoteles cinco estrellas, pues los años de experiencia que poseen en la actividad turística o vinculada a ésta, les permiten estar a tono con el desarrollo del entorno objeto de la investigación. Se desarrollaron talleres los cuales facilitaron el intercambio de ideas y opiniones en torno a la investigación. 


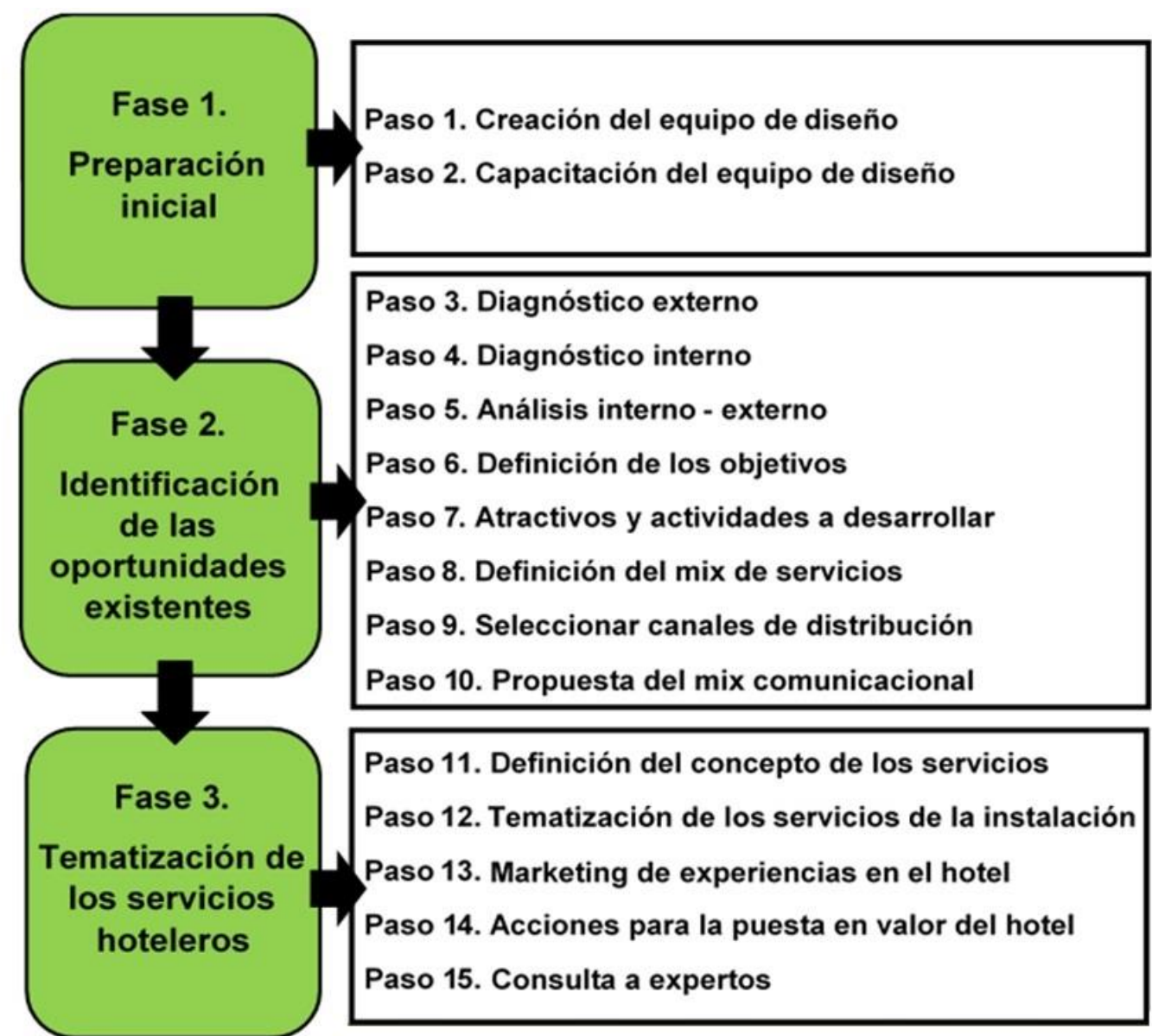

Figura 1. Procedimiento para el diseño de la tematización de servicios hoteleros

Fuente. Elaboración propia a partir del procedimiento propuesto por Hidalgo-González (2018) para el diseño de los servicios del Hotel Vallado en Gibara

\section{Fase 2. Identificación de las oportunidades existentes}

El éxito de una organización depende en gran medida de la capacidad que tenga de hacer frente a las amenazas del entorno y aprovechar las oportunidades que este brinda. Por ende, el diagnóstico externo se centra en analizar aquellos factores del entorno tanto del ámbito nacional como internacional que puedan repercutir de forma positiva o negativa en el futuro de la organización y para ello se consideran cinco aspectos fundamentales: Económico, demográfico, tecnológico, político-legal y sociocultural-medioambiental.

A nivel internacional destacan: la crisis económica mundial que ha provocado durante los últimos años innumerables daños a la sociedad; el envejecimiento poblacional que trae potenciales implicaciones sobre la desestacionalización de los flujos turísticos; el constante crecimiento de las Tecnologías de la Información y las Comunicaciones (TICs) hace que todo lo relacionado con el destino turístico (desde la selección hasta el consumo) se realice de una manera rápida, ágil y segura, etc. La existencia del bloqueo económico hacia Cuba que ha provocado restricciones financieras que limitan la operación entre 
bancos cubanos y norteamericanos. En lo sociocultural-medioambiental, se acentúa el incremento de la proporción de mercados emisores pues los clientes disponen de menos tiempo para realizar los viajes, con lo cual buscan disfrutar de un máximo de productos en un mínimo de tiempo. Y finalmente el cambio climático, ha generado la destrucción de disímiles atractivos turísticos, tales como playas, bosques, museos, entre otros; así como graves afectaciones a la biodiversidad del planeta.

En el ámbito nacional, los Lineamientos de la Política Económica y Social del Partido y la Revolución para el período 2016 - 2021 y el documento de Conceptualización del Modelo Económico y Social Cubano de Desarrollo Socialista, aprobados en el 2017 por el VII Congreso del Partido Comunista de Cuba, están encaminados al desarrollo sostenible del país. Específicamente, los referidos a la Política para el Turismo, definen como objetivo fundamental de la misma la captación de divisas frescas con una posición competitiva en el mercado. El bloqueo económico contra Cuba por parte de EE. UU ha generado incontables daños a la economía nacional, lo cual dificulta el acceso a las tecnologías de punta y encarece los productos en el mercado. En lo referente a la demografía, el sistema de salud gratuito permite tener una alta esperanza de vida al nacer, una baja tasa de mortalidad infantil y que el promedio de vida de la población esté por encima de los 75 años. La industria turística ha experimentado cambios tecnológicos, lo que le ha permitido diversificar la oferta, sin embargo, resultan insuficientes los servicios de comunicación en el sector. Una de las principales razones de viaje de los clientes que visitan el país es la seguridad que el mismo brinda, y uno de los atractivos es su política que lo convierte en un país libre de violencia a nivel mundial. Aunque el archipiélago, por su posición, está propenso al azote de fenómenos meteorológicos de gran magnitud; sin dudas, su ubicación geográfica y características climatológicas se convierten en oportunidad para el desarrollo del turismo. Además, Cuba se caracteriza por tener una mezcla de raíces culturales y un pueblo culto, en su gran mayoría profesionales. La idiosincrasia del cubano y la defensa de sus tradiciones son unos de los mayores atractivos para el destino.

El diagnóstico externo también permitió comprobar la existencia de un mercado atractivo al cual dirigir la oferta, con vistas a ocupar un buen posicionamiento frente a la competencia y se partió de diagnosticar la situación actual de Gibara como destino turístico, determinando las oportunidades para el diseño de la tematización de los servicios del Hotel Residencial, un hotel diferente, original, monumental y sostenible, que satisfaga las necesidades de sus clientes, sea rentable económicamente y contribuya a la diferenciación y diversificación de la oferta existente en el destino.

A partir del estudio de los principales mercados emisores que han llegado a Gibara en los dos últimos años, considerando el comportamiento del arribo de clientes al destino por concepto de excursiones, las visitas de prospección y grupos FAM durante el desarrollo del Festival Internacional de Cine, la presencia en el destino del famoso You Tuber Alan x el mundo, con excelentes comentarios en la red; al hacer un análisis del perfil de los principales mercados del destino, se determina como mercado meta el mercado alemán, por ser uno de los que más visita la ciudad de Gibara por concepto de alojamiento en 
hoteles de ciudad, con intereses de comprar productos histórico-culturales y por ser un mercado en crecimiento al cual fue dedicada la FIT Cuba 2017, pues gusta de la modalidad de circuitos y actualmente es el turista que más gastos promedio tiene durante sus viajes así como mayor promedio de estancia en el destino.

El análisis de la competencia se realizó enfatizando en la tematización del resto de las instalaciones hoteleras del destino basada en el concepto de los servicios que las mismas proponen, determinándose que el principal competidor del Hotel Residencial es el Hotel Ordoño, el cual tiene mejor implementado en la práctica el argumento central de su tematización y lo emplea como elemento del marketing de experiencias para fidelizar con sus clientes. No obstante a ello, el Residencial se encuentra en una posición favorable pues su tematización no solo será con elementos nacionales o propios de la instalación, como se ha venido desarrollando hasta ahora en el destino, sino que poseerá una mezcla combinada de estos elementos de conjunto con los internacionales, considerando el tema central propuesto para dicha tematización: las maravillas del mundo antiguo y moderno, las ciudades maravillas, las maravillas de la arquitectura cubana y las de Gibara.

Las potencialidades que avalan a Gibara y su entorno como destino turístico se concentran en una gran variedad de recursos turísticos, que se encuentran ubicados en cuatro espacios: litoral, urbano, natural y rural; en cada uno de los cuales se dispone de variados atractivos naturales y socio-culturales asociados a las temáticas de turismo náutico, turismo urbano, turismo de naturaleza y turismo rural, a los que se les unen las modalidades de turismo de sol y playa y el turismo de salud.

También son llamativas las tradiciones locales cuya riqueza se expresa en una rica oralidad, que caracteriza a todas las generaciones desde el siglo XIX y que para el siglo $\mathrm{XX}$ es sin dudas una de sus joyas culturales, recogida en varias publicaciones que aseguran su protección y permanencia. El signo predominante de la cultura tradicional popular radica en esta expresión, que incluye versos, poemas, canciones, coplillas, cuentos, leyendas urbanas y rurales y un anecdotario único en el país. Igualmente destacan su típica gastronomía, los pregones gibareños y la Fiesta del Gibareño Ausente. Posee además una rica arquitectura monumental -la cual avala su Centro Histórico declarado como Monumento Nacional desde el año 2004- influenciada por la presencia de la cultura española en la isla, ejemplo son la Batería Fernando VII, la Casa de Cultura Félix Varona Sicilia, el Parque Calixto García, el Monumento a Emilio Laurent, el Teatro Colonial, el Museo de Artes Decorativas, la Iglesia Católica, entre otras.

La oferta turística de Gibara tiene como eje central los valores tradicionales y del patrimonio de la localidad, la cual representa uno de los lugares de mayor atracción para la aplicación de un modelo que permita fomentar el desarrollo de productos turísticos locales, debido a sus espacios naturales, patrimoniales e históricos-culturales.

Como cierre de esta parte del diagnóstico se construye la Matriz de Evaluación de Factores Externos (MEFE), para lo cual se identificaron las oportunidades y amenazas del entorno, obteniéndose un total ponderado de 2.92 , lo que pone de manifiesto que el nuevo producto se desarrollará en un entorno externo favorable. 
Luego de realizar el diagnóstico externo se analiza la situación interna de la instalación con el objetivo de determinar las fortalezas y debilidades que constituyen factores claves de éxito; así se parte de la caracterización histórica de la instalación y se analizan los criterios de diseño y proyecto arquitectónico a seguir, con lo cual se define la capacidad habitacional, las áreas que formarán parte de la instalación y los requerimientos establecidos para cada una, considerando la categoría de la misma.

La caracterización histórica de la edificación permite conocer que la futura instalación estará ubicada en una de las construcciones civiles de mayor prestancia y monumentalidad en la Villa que fue el primer edificio de estilo ecléctico construido en la ciudad, lo que le otorga la condición de una de las siete maravillas de la arquitectura de Gibara. Es uno de los pocos inmuebles con dos niveles, cuya planta presenta dos patios interiores y en el cual, aunque predominan los códigos neoclásicos, hay una marcada influencia de la arquitectura tradicional.

La edificación, conocida popularmente como La Murcielaguina, a lo largo de su historia ha servido de sede a múltiples instituciones como: la Sociedad Colonia Española, una escuela pública, la Junta de Educación, comercios y un hotel. Así mismo, ha sido escenario de hechos importantes para la localidad, uno de ellos fue la visita del entonces presidente de Cuba Don Tomás Estrada Palma y la huelga estudiantil en demanda de una escuela superior y de la construcción de la carretera de Gibara a Holguín.

En una visita a la ciudad realizada por el Dr. Eusebio Leal en el año 2002, al divisar las entonces ruinas del edificio desde el balcón del Museo Municipal de Artes Decorativas expresó: ¡Tengo ante mis ojos la Pompeya y Herculano de la Italia antigua!, atribuyéndole a aquel viejo inmueble el aspecto místico de las ciudades mencionadas.

Por su parte, el criterio general de diseño plantea que teniendo en cuenta la localización, el valor histórico-cultural y arquitectónico, se propone la rehabilitación del viejo inmueble, de manera que se pueda rescatar el mismo en su totalidad para conservar su concepción arquitectónica original y su fachada, construyendo un edificio de cuatro niveles más una azotea con snack bar y piscina desde la cual se podrá disfrutar de servicios de restauración ligeros y gran diversidad de tragos a la vez que se podrá apreciar una espectacular vista de la ciudad, desde el que será el edificio más alto del Centro Histórico Urbano. Se dispondrá de una capacidad de 42 habitaciones, conformadas entre el segundo y el cuarto nivel, niveles en los que además se contará con locales para las camareras, sala de juego, salón multipropósito y ascensor para mayor accesibilidad a todos los niveles del hotel. El nivel bajo de la edificación contará con los servicios administrativos, gastronómicos, públicos, tecnológicos, almacenes, tiendas y galerías.

Se cierra el análisis de la situación interna de la instalación con el empleo de la Matriz de Evaluación de Factores Internos, cuyo resultado total ponderado de 3.18 demuestra que existe un predominio de las fortalezas sobre las debilidades, lo que permite concluir que la situación interna del producto propuesto es favorable.

Para comparar los resultados obtenidos en los respectivos diagnósticos y determinar las estrategias a seguir para lograr el éxito del nuevo producto, se construye la Matriz Interna- 
Externa en la cual el producto se ubicó en el cuadrante IV de fortalezas y oportunidades, por lo que se recomienda seguir estrategias ofensivas o de crecimiento y desarrollo.

A partir de lo analizado anteriormente se definen como objetivos de la instalación los siguientes:

1. Diversificar y diferenciar la oferta existente en el territorio utilizando los detalles en la tematización del hotel para así ganar posicionamiento frente a la competencia.

2. Aprovechar los valores histórico-culturales del destino para crear ofertas que los vinculen directamente con las actividades recreativas hoteleras y extra hoteleras.

3. Contribuir a incrementar los ingresos y utilidades del sector turístico en el territorio y por ende en la región.

4. Lograr altos índices de satisfacción en los clientes para garantizar la fidelización y repitencia de los mismos.

E igualmente se proponen las posibles actividades a desarrollar como complemento a la oferta con el objetivo de añadirle valor al producto, para ello se tuvieron en cuenta aspectos como la accesibilidad, autenticidad, distancia en relación con el hotel de los recursos disponibles y posibilidades de realizar actividades complementarias en los mismos, tomando como base los valores patrimoniales del hotel y de la ciudad de Gibara así como los atractivos disponibles (ver Anexo 1).

Determinados los atractivos de la instalación, las características del mercado meta seleccionado y los beneficios que brinda el entorno, se define entonces como servicio principal del Hotel Residencial Gibara el siguiente: Brindar servicios de alojamiento, restauración y recreación donde el lujo y la distinción se conjugan con altos estándares de calidad, personalización y excelencia, para responder a las nuevas demandas de un cliente cada vez más exigente, creándole un producto que no solo se limite al descanso, sino también lo envuelva en una experiencia inigualable que, al escuchar sobre Siete Maravillas, vendrá a su mente la perfecta mezcla de historia, cultura y arquitectura vivida en este espacio creado para los amantes del conocimiento y el buen gusto.

Para la selección de los canales de distribución se tuvieron en cuenta las agencias de viajes y turoperadores de mayor significación que operan en el destino con el mercado meta seleccionado, sin descartar las ventas directas y el uso de internet.

- Agencias de Viajes (AA.VV)

- El nuevo producto debe ser presentado en las reuniones mensuales que se desarrollan en la Asociación Cubana de Agencias de Viajes (ACAVI) a los representantes de las mismas, realizando todas las acciones necesarias para que este resulte aprobado. Además, se puede comunicar el producto en la reunión de conformación del catálogo que se realiza en el destino.

- Tour operadores (TT.OO)

- Establecer relaciones contractuales con los directivos y representantes de los principales turoperadores que operan en el destino, y otros potenciales que 
pudieran interesarse por mover flujos de clientes al mismo, para incidir positivamente en la venta del nuevo producto.

- Ventas directas

- Es importante establecer una buena relación vendedor-consumidor una vez que un cliente llegue al hotel y muestre interés pues el marketing directo o las técnicas de merchandising influyen en la decisión de compra; en lo cual el rol del recepcionista es fundamental, debe poseer amplios conocimientos sobre la historia del inmueble y la localidad; así como, dominar a la perfección todo lo referente a la tematización de la instalación y comunicar además las actividades complementarias a la oferta dentro del hotel y en el entorno ampliado.

- Para dar a conocer el producto y motivar su compra, se empleará una combinación adecuada de instrumentos y técnicas para la comunicación comercial y la promoción.

- Uso de internet

- Se propone la creación de un perfil del hotel en las redes sociales Facebook y Twitter donde se anuncien las ofertas especiales, se realicen invitaciones a personalidades líderes de opinión y permitan de manera general estar en contacto directo con el público objetivo. Se propone también que en la página del centro de información turística (INFOTUR) aparezcan fotos del hotel con información detallada de la oferta.

- Acciones promocionales para agencias de viajes y turoperadores

- Presentar el producto en ferias turísticas como FIT Cuba y otras de menor categoría en los distintos destinos del país.

- Aprovechar los Fam Trip (viajes de familiarización) que ya se realizan en el destino, así como gestionar la ampliación de los mismos para presentar el producto "in situ" a los representantes del tour operadores.

- Aprovechar el marco de los eventos que se realizan en la ciudad para insertar el producto en el programa de actividades en coordinación con las comisiones encargadas de la organización y realización de los mismos.

- Acciones promocionales para clientes

- Realizar una campaña publicitaria a través de las redes sociales.

- Incluir el producto en guías, afiches, folletos y catálogos del destino.

- Ubicar sueltos que comuniquen con exactitud los atractivos del producto, en el aeropuerto Frank País y en los mostradores de ventas de las instalaciones del destino (hoteles, tiendas, etc.).

- Mostrar videos de los atractivos del hotel durante el traslado del aeropuerto al mismo.

- Emplear como parte del uniforme de los trabajadores, solapines especialmente diseñados para la instalación.

- Coordinar trabajos con la prensa provincial, nacional y especializada.

- Implementar un canal interno en el hotel donde se muestren videos e imágenes de los principales atractivos de la ciudad. 


\section{Fase 3. Tematización de los servicios del hotel residencial gibara}

Con base en todo lo hasta aquí analizado, se define el concepto de servicios hoteleros siguiente: Distinción, buen gusto, lujo y confort se fusionan con historia y arquitectura para crear un producto único e incomparable que dejará huella en la mente de todo aquel que visite el antiguo edificio ecléctico de inicios del siglo XX conocido popularmente como La Murcielaguina donde hoy se erige el majestuoso y monumental Hotel Residencial Gibara que te permitirá disfrutar de una experiencia inolvidable a la vez que conocerás, en un solo espacio, lo que la historia no te ha permitido vivir, transitando por las maravillas del mundo antiguo, moderno, ciudades maravilla y las cubanas hasta llegar a las que sí podrás ver y palpar: las maravillas de la arquitectura de la hermosa ciudad de Gibara, en una de las cuales te encuentras para disfrutar de una estancia placentera con servicios personalizados y altos estándares de alojamiento, restauración y recreación.

La tematización de los servicios de la instalación se realizará por niveles, en el caso del primer nivel, el tema escogido es las Siete Maravillas del Mundo Antiguo y en el mismo se ubicarán el lobby y la tienda, entre otros servicios.

El lobby: Se emplearán, obras planas relacionadas con las maravillas de la antigua Grecia, mobiliario de diversos estilos y diseños que se correspondan, de ser posible con los empleados en este país, así como objetos relacionados con dicha temática. Al acceder a este espacio, en su centro se encontrará, dando la bienvenida al huésped, una fuente de tamaño mediano que integre el famoso Coloso de Rodas y la Estatua del dios Zeus, ambas maravillas de la antigua Grecia.

Tienda y galería Las Turcas: Perteneciente a la Cadena Caracol, dedicada a la venta de suvenires, postales, guías turísticas, plegables del destino y artículos de primera necesidad para los clientes. Se le propone como nombre, en honor a las maravillas turcas restantes de las siete del mundo antiguo. Por lo tanto, para su decoración se dispondrá de fotos y pinturas referentes al Mausoleo de Halicarnaso y el Templo de Artemisa.

\section{Servicios de alojamiento}

El hotel dispondrá de 42 habitaciones y se propone que los pasillos que conllevan a estas, estén decorados con obras referentes para ir vinculando al cliente con la temática de su habitación.

El segundo nivel estará dedicado a las Nuevas Siete Maravillas del Mundo Moderno, tema que será visible desde el instante en que el cliente arriba a este nivel. Para ello se propone dividir las habitaciones presentes en siete grupos, que se pudieran llamar rincones y tematizar cada uno de los rincones con fotos e imágenes de cada una de las mismas de manera que el cliente que se hospede sea capaz de sentir que se encuentra en este país y frente o cerca a la maravilla tema de su habitación. Además, los pasillos que conducirán a dichos rincones estarán decorados a modo de transición de un lugar a otro, indicando el paso por los diferentes lugares. Para la decoración de pasillos y habitaciones, además de las obras planas se proponen réplicas en miniatura y objetos relacionados con el tema. En todas las habitaciones se incluirán postales con imágenes y descripciones de 
la historia de la maravilla tema de la habitación en los cuatro idiomas principales: español, inglés, alemán y francés.

El tercer nivel se dedicará a las Siete Ciudades Maravillas del Mundo y su tematización se realizará de la misma manera que el nivel anterior, con un elemento adicional: al ser ciudades, se propone que los rincones sean tematizados cada uno con elementos autóctonos o lugares de estas ciudades, de manera que cada rincón refleje casi en su totalidad lo más representativo de la ciudad de que se trate. De igual manera se colocarán postales con imágenes y descripciones de la historia de la ciudad maravilla tema de la habitación, en los cuatro idiomas principales.

El cuarto nivel habitacional se tematizará con las Siete Maravillas de la Arquitectura Cubana procediendo de la misma manera que los niveles anteriores, se pueden agregar otros elementos típicos de las ciudades donde se encuentran las maravillas para diversificar la tematización. Este podría definirse como el nivel de la arquitectura cubana, pues todos sus exponentes son representaciones de la misma.

\section{Servicios de restauración}

La propuesta de los servicios de restauración se centra en la variada oferta de bebidas y alimentos presentes en el restaurante Maravillas egipcias, el bar Jardines Colgantes y el snack bar-piscina Fernando VII.

Restaurante Maravillas egipcias: Ubicado en el primer nivel, su nombre hace mención a la famosa Pirámide de Guisa y el Faro de Alejandría, ambas consideradas maravillas del mundo antiguo, y ubicadas en dicho país. El mismo se especializará en comida cubana e internacional y no pueden faltar en su menú platos típicos que recreen los de la cocina tradicional egipcia como son el Ful medames para enriquecer la oferta de entrantes calientes y las Meneas como delicioso postre, además tomarán protagonismo los platos típicos de la cocina gibareña, encabezados por la especialidad de la casa Maravillas del mar, un plato elaborado a base de siete delicias del mar (camarón, jaiba, cangrejo, pescado, langosta, calamar y mejillones). Su decoración se basará fundamentalmente en obras planas (fotografías y pinturas) de estas maravillas, plegables con su descripción e historia, así como de otros platos de la comida egipcia que se adecuen en su preparación a las condiciones culinarias de este tipo de instalación.

Bar Jardines colgantes: Igualmente se ubica en el primer nivel y su nombre hace honor a esa maravilla de la Babilonia antigua, integrará plantas ornamentales en su estructura con elementos similares a los originales. También estará decorado con fotografías y pinturas acordes a la temática. Además, se expenderá como coctel de bienvenida el Maravilla Tropical, una bebida elaborada sobre la base de jugo y licor de piña, licor marrasquino y una cava o vino blanco espumoso, respondiendo a las nuevas tendencias del mercado europeo, que buscan cocteles a base de jugos naturales, perfumados y escasos en alcohol. Además, el café Maravillas como especialidad de la casa en este tipo de servicio, un café elaborado en perfecta mezcla de café español con tres leches. De igual modo se proponen las noches babilonias, donde la oferta de bebidas estará basada en las cervezas y los vinos, bebidas típicas de la región. 
Snack Bar- Piscina Fernando VII: Estará en el quinto nivel, nivel dedicado a las Maravillas de la Arquitectura Gibareña, de ahí su nombre que corresponde con la primera de dichas y desde la visual que ofrece es posible divisar cada una de ellas, lo cual podría lograrse con la instalación de un catalejo. Su decoración estará basada en obras planas que reflejen la historia y transición en el tiempo de lo que fueron en el pasado y lo que son en el presente. Se expenderán recetas típicas de la cocina tradicional gibareña como es el caso de las jaibitas rellenas, cocteles de camarones, ostiones y jaiba, frituras de coquina, camarón y pescado y croquetas de mariscos para acompañar la gran variedad de tragos que se ofrecerán.

\section{Servicios De Recreación}

El cliente dispondrá en el quinto nivel de piscina con jacuzzy a uno de sus laterales. Contará además con área techada y al aire libre para el disfrute de las espectaculares que ofrece la ciudad, su particular arquitectura y su teatral bahía.

El programa recreativo cultural del hotel se diseñará en varias vertientes: para días de semana, fines de semana, fechas conmemorativas y jornadas festivas, cuyas actividades se planificarán de acuerdo a la ocupación prevista y al tipo de mercado. Se prevé emplear para la animación la presentación del talento local fundamentalmente, aunque no se descarta la participación de algunos artistas foráneos.

En busca de explotar al máximo las actividades que generan experiencias memorables y aprovechando su ubicación geográfica, el hotel promoverá a través del buró de información, la visita de los clientes a los museos y otros sitios de interés de la ciudad que destaquen por sus valores tradicionales y del patrimonio. Así mismo, se recomendará la realización de la ruta turística del Festival Internacional de Cine, conocida como Andar con Solás.

Se propone la confección de postales basadas en las fotos de las maravillas, tanto locales como nacionales e internacionales, lugares en que se encuentran y otros elementos de interés referidos al tema. Las mismas podrán ser empleadas además como parte del Plan de Fidelización del Cliente. Así mismo, se recomienda, como complemento a la oferta, desarrollar el recorrido cultural Siete Maravillas Gibareñas, donde el cliente podrá adquirir un conocimiento general de los principales exponentes de la arquitectura local.

Además, se sugiere la venta y/u obsequio de suvenires a través de la tienda Las Turcas que identifiquen la instalación de manera personalizada: en el caso de las mujeres se les entregará una polvera de madera o pañuelo bordado confeccionados por artesanos locales y a los hombres un llavero de hueso. Ambos objetos llevarán grabados, de ser posible, el nombre del hotel, así como su logotipo.

Conocer las siete maravillas del mundo antiguo es algo casi imposible por su condición constructiva actual, la cual se encuentra en ruinas en su mayoría; las del mundo moderno se pueden conocer, pero eso implicaría viajar a siete ciudades diferentes, igual ocurre con las ciudades maravillas del mundo. Las maravillas cubanas y las de Gibara se pueden 
conocer en un solo viaje al destino Cuba; pero conocer todo lo antes mencionado en un solo espacio y a un mismo tiempo no es algo que se puede realizar todos los días.

Para que el cliente que visite el hotel sea capaz de disfrutar de una experiencia nunca antes vivida y quede en su mente por encima de las experiencias anteriores, es necesario que el personal de la instalación, máximos responsables de propiciar esa emoción se sientan comprometidos y trabajen en aras de proveer la sensación inesperada al público. Para lograrlo es necesario que todos los procesos (claves, estratégicos y de apoyo) trabajen alineadamente, jugando un papel fundamental las relaciones públicas y el personal de recepción, máximos responsables de la imagen de la instalación. Debe poseerse basto conocimiento de la historia local y universal, especialmente la referida a la temática sobre la cual gira el hotel.

Como elemento clave se debe prestar especial atención a la tematización propuesta para cada una de las áreas del hotel, así como a la oferta gastronómica si se pretende crear un producto diferenciado con la capacidad de sorprender y lograr un vínculo positivo con el cliente, que haga que este lo prefiera por encima de la competencia.

Finalmente, para la puesta en valor del producto Hotel Residencial Gibara se elaboró un plan de acción que contiene cada una de las actividades a desarrollar, los responsables de realizarlas y la fecha de cumplimiento de las mismas. El plan fue elaborado en dos vertientes fundamentales: las acciones de implementación y monitoreo para la puesta en valor del producto y las encaminadas a la fidelización del cliente (ver Anexo 2)

Una vez definido el mix de servicios y la tematización de cada una de los servicios se llevó a cabo la evaluación por parte de los expertos. La misma se estructuró en dos partes fundamentales, una primera evaluación cualitativa que consistió en la aplicación de un test donde se expone de forma simple y detallada la propuesta realizada para determinar su nivel de aceptación por parte del grupo de especialistas; y concluye con una evaluación cuantitativa, donde los expertos otorgan valores numéricos a cada una de las etapas de la investigación, y esto a su vez se traduce en una escala que califica la propuesta de la investigación.

La aplicación del test arrojó como resultado que la propuesta de tematización de servicios del nuevo producto turístico satisface las necesidades e intereses de los mercados meta seleccionados. Así mismo, los especialistas aseguraron recomendarían a los TTOO, AAVV y clientes finales este hotel, a la vez que emitieron a modo de sugerencias para mejorar el producto, las siguientes:

- Gestionar con el Gobierno Municipal y con Servicios Comunales la limpieza sistemática del Centro Histórico Urbano, y por ende, el resto de la ciudad.

- Gestionar la implementación del proyecto aprobado que comprende la reparación del vial Gibara - Holguín y las principales arterias de la ciudad.

- Tramitar proyectos dirigidos a la restauración de los principales edificios coloniales de la ciudad de Gibara y agilizar la restauración del teatro colonial y el Museo de Historia Municipal. 
- Gestionar con el Museo de Historia Municipal para que faciliten personal capacitado en historia y los idiomas de los diferentes mercados para la realización del recorrido Siete Maravillas Gibareñas.

- Coordinar con las autoridades correspondientes la disminución del asedio a los visitantes en el centro de la ciudad.

- Gestionar con Cultura Municipal la vinculación de sus actividades culturales a la oferta recreativa extra hotelera de la instalación.

- Gestionar con AAVV y dirección del Mintur en la provincia la inclusión de Gibara en los recorridos por mar para de esta manera aumentar el flujo de clientes y, por ende, el conocimiento del destino a mayor escala.

- Incrementar las actividades de promoción del destino.

Para garantizar la retroalimentación continua y evaluación del proceso de diseño de los servicios turísticos propuesto se realizó un control parcial por etapas. A cada uno de los indicadores seleccionados se les otorgaron calificaciones del 1 al 5 (escala de Likert), donde 1 es el menor valor y 5 el de mayor valor. Se determinaron los indicadores siguientes:

- En la segunda etapa: Identificación de las oportunidades existentes considerando: 1. Mercado meta con interés, posibilidad y disposición para obtener un producto turístico cultural.

2. Nivel de atracción de los recursos turísticos existentes en la zona objeto de estudio.

3. Posibilidad de satisfacer las necesidades, intereses y deseos del público objetivo mediante los servicios del nuevo producto.

4. Posibilidad de que la comunicación comercial de a conocer el producto al público objetivo y motive su compra.

- En la tercera etapa: Tematización de los servicios hoteleros considerando:

5. Posicionamiento favorable frente a la competencia.

6. Exclusividad y originalidad de la tematización propuesta.

7. Posibilidad de brindar experiencia a través del tema central.

8. Efectividad y alcance del Plan de Acciones.

Para evaluar los indicadores se realizó la matriz variable - evaluación de los especialistas en el programa Microsoft Excel. Luego, se introdujeron los valores de la evaluación dada por el grupo de especialistas en la matriz.

Para procesar la información se utilizó una medida de tendencia central (media) con el objetivo de obtener el valor medio del conjunto de evaluaciones dada por los especialistas, definido como Índice de Evaluación del Diseño del Producto (IEDP). 
El análisis arrojó los resultados siguientes:

La segunda etapa obtuvo un índice de evaluación de un 4.53, lo que significa que fue evaluada de excelente por los especialistas.

La evaluación de la tercera etapa fue de 4.71, lo que significa que los especialistas consideran que sus resultados también son excelentes.

Al realizar un análisis de los resultados obtenidos de la evaluación del diseño del producto en cada una de sus etapas, calculando el promedio de dichos resultados se puede concluir que el producto está en la escala de excelente, con un índice de evaluación del diseño del producto de 4.62. Esto evidencia que la tematización de los servicios propuesta para el Hotel Residencial Gibara es exclusiva, de calidad y puede satisfacer las necesidades del público objetivo, se encuentra en una posición relativamente ventajosa frente a la competencia existente y posee un buen sistema de comunicación comercial.

\section{Conclusiones}

El cumplimiento del objetivo general de la presente investigación, así como la elaboración y aplicación de un procedimiento para el diseño de la tematización de los servicios hoteleros, ha permitido arribar a las conclusiones siguientes:

- El tema investigado se encuentra en consonancia con lo trazado en el Programa de Desarrollo Municipal y lo planteado en la Actualización de los Lineamientos de la Política Económica y Social del Partido y la Revolución para el período 2016-2021, en lo referente a la Política para el Turismo, aprobados en el VII Congreso del Partido en abril de 2016.

- La diversificación y diferenciación de ofertas turísticas a través de la tematización de los servicios hoteleros es una herramienta moderna y de gran utilidad, especialmente en destinos como Gibara, que comienzan su actividad turística en un entorno influenciado por fuertes competidores y buscan ganar preferencia por parte de nuevos mercados.

- La situación existente en el entorno favorece el desarrollo de la propuesta de tematización realizada por dos razones fundamentales: la existencia de un abanico de recursos y atractivos disponibles para complementar la oferta y de un segmento de mercado que muestra interés por el consumo de este tipo de productos.

- La tematización de los servicios del Hotel Residencial Gibara, de conjunto con las características propias de dicho hotel, será la mezcla perfecta de lujo e historia capaz de satisfacer las exigencias de los diferentes mercados a la vez que contribuirá a diversificar y diferenciar la oferta turística de la ciudad de Gibara.

\section{Referencias bibliográficas}


Fernández-Serrano, C. (2018). El marketing experiencial como herramienta de fidelización. (Trabajo de fin de grado en opción al título de Publicidad y Relaciones Públicas), Universidad Autónoma de Barcelona, España.

García-Garazo, T. (2004). Orientación al servicio de los hoteles de Galicia: efecto de la categoría, localización y pertenencia a una cadena. Revista Gallega de Economía, 13(1-2), 1-19.

García, E. (2013). La experiencia creativa, el mejor recuerdo del viaje. Publicado en Sinergia Insular. Descargado de: https://sinergiainsular.wordpress.com/2013/11/11/la-experiencia-creativa-elmejor-recuerdo-del-viaje

González-Sainz, Y., Cardet-Fernández, E. \& Palao-Fuente, R. (2019). Hotel Plaza Colón, diferenciador de la oferta turística de Gibara. Revista Electrónica Explorador Digital, 3(1), 23-30. Descargado de: http://webcache.googleusercontent.com/search?q=cache:IhUhXeTnM6sJ:ciencia digital.org/revistacienciadigital2/index.php/exploradordigital/article/download/3 $43 / 755 /+\& \mathrm{~cd}=1 \& \mathrm{hl}=\mathrm{es} \& \mathrm{ct}=\mathrm{clnk} \& \mathrm{gl}=\mathrm{cu}$

Graña-Mariño, G. (2017). Diseño de los servicios del Hotel E Bahía del Almirante en Gibara. Trabajo de Diploma en opción al título de Licenciado en Turismo, Facultad de Ciencias Empresariales y Administración, Universidad de Holguín, Cuba.

Hidalgo-González, Y. (2019). Diseño de los servicios del Hotel Vallado en Gibara. Trabajo de Diploma en opción al título de Licenciada en Turismo, Facultad de Ciencias Empresariales y Administración, Universidad de Holguín, Cuba.

Jiménez-Gómez, M. (2012). Propuesta de diseño de los servicios del Hotel Ordoño en el Municipio Turístico Gibara. Trabajo de Diploma en opción al título de Licenciada en Turismo, Facultad de Ingeniería Industrial, Universidad de Holguín, Cuba.

Menéndez-López, J. (2018). Diseño, marca y tematización de hoteles. Descargado de: http://jesusmenendezlopez.wordpress.com/2018/04/22/diseno-marca-ytematizacion-de-hoteles/. Consultado el 13 de marzo de 2019

Partido Comunista de Cuba. (2017). Documentos del 7mo. Congreso del Partido. La Habana, Cuba: Tabloides I y II. La Habana: UEB Gráfica Empresa de Periódicos, Cuba.

Velázquez-San Martín, M. (2015). Diseño de los servicios del Hotel E Saratoga Holguín. Trabajo de Diploma en opción al título de Licenciado en Turismo, Facultad de Ingeniería Industrial y Turismo, Universidad de Holguín, Cuba. 
Vinent-Ferrer, O. (2016). Diseño de los servicios del Hotel E Imperial de Santiago de Cuba. Trabajo de Diploma en opción al título de Licenciado en Turismo, Facultad de Ingeniería Industrial y Turismo, Universidad de Holguín, Cuba.

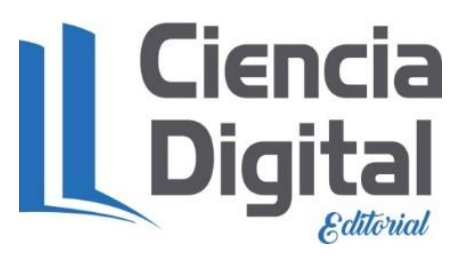




\section{PARA CITAR EL ARTÍCULO INDEXADO.}

Cardet Fernández, E., Ricardo Miranda, A. S., \& Ricardo Miranda, A. S. (2021). Tematización de los servicios hotel residencial Gibara, apuesta al turismo cultural desde el destino Holguín. Explorador Digital, 5(1), 416-436. https://doi.org/10.33262/exploradordigital.v5i1.1511

\section{Liencia}

El artículo que se publica es de exclusiva responsabilidad de los autores y no necesariamente reflejan el pensamiento de la Revista Explorador Digital.

El artículo queda en propiedad de la revista y, por tanto, su publicación parcial y/o total en otro medio tiene que ser autorizado por el director de la Revista Explorador Digital.
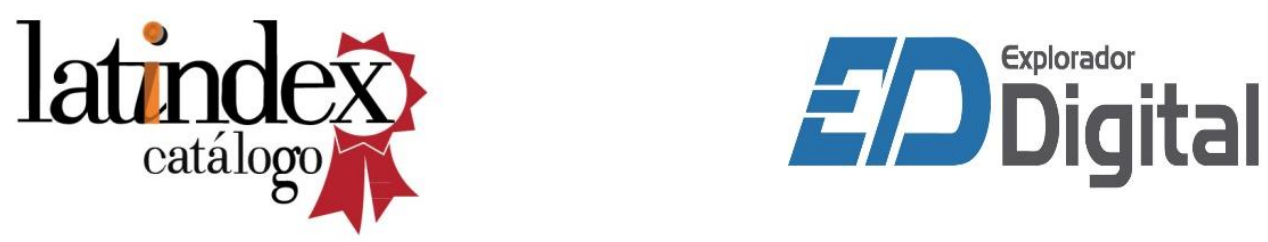